\title{
Statistical Analysis of Network Based Issues and Their Impact on Social Computing Practices in Pakistan
}

\author{
Zahoor Hussain ${ }^{1 *}$, Zulfiqar Ali Bhutto1, Gulab Rai², Majid Hussain ${ }^{3}$, Kashif Zaheer ${ }^{4}$ \\ ${ }^{1}$ Institute of Information and Communication Technology, University of Sindh, Jamshoro, Pakistan \\ ${ }^{2}$ Education \& Literacy Department, Government of Sindh, Karachi, Pakistan \\ ${ }^{3}$ Bahria University, Karachi Campus, Pakistan \\ ${ }^{4}$ Department of Computer Science, Karachi University, Karachi, Pakistan \\ Email: *zahoorshah@scholars.usindh.edu.pk, zul?qar.bhutto@usindh.edu.pk, raigulab22@gmail.com, bhattiindus@gmail.com, \\ kazah_83@hotmail.com
}

How to cite this paper: Hussain, Z., Bhutto, Z.A., Rai, G., Hussain, M. and Zaheer, K. (2016) Statistical Analysis of Network Based Issues and Their Impact on Social Computing Practices in Pakistan. Journal of Computer and Communications, 4, 23-39. http://dx.doi.org/10.4236/jcc.2016.413003

Received: August 20, 2016

Accepted: October 15, 2016

Published: October 18, 2016

Copyright $\odot 2016$ by authors and Scientific Research Publishing Inc. This work is licensed under the Creative Commons Attribution International License (CC BY 4.0).

http://creativecommons.org/licenses/by/4.0/

\begin{abstract}
Social computing and online groups have accompanied in a new age of the network, where information, networking and communication technologies are enabling systematized human efforts in primarily innovative ways. The social network communities working on various social network domains face different hurdles, including various new research studies and challenges in social computing. The researcher should try to expand the scope and establish new ideas and methods even from other disciplines to address the various challenges. This idea has diverse academic association, social links and technical characteristics. Thus it offers an ultimate opportunity for researchers to find out the issues in social computing and provide innovative solutions for conveying the information between social online groups on network computing. In this research paper we investigate the different issues in social media like users' privacy and security, network reliabilities, and desire data availability on these social media, users' awareness about the social networks and problems faced by academic domains. A huge number of users operated the social networks for retrieving and disseminating their real time and offline information to various places. The information may be transmitted on local networks or may be on global networks. The main concerns of users on social media are secure and fast communication channels. Facebook and YouTube both claimed for efficient security mechanism and fast communication channels for multimedia data. In this research a survey has been conducted in the most populated cities where a large number of Facebook and YouTube users have been found. During the survey several regular users indicate the certain potential issues continuously occurred on these social web sites interfaces, for
\end{abstract}


example unwanted advertisement, fake IDS, uncensored videos and unknown friend request which cause the poor speed of channel communication, poor uploading and downloading data speed, channel interferences, security of data, privacy of users, integrity and reliability of user communication on these social sites. The major issues faced by active users of Facebook and YouTube have been highlighted in this research.

\section{Keywords}

Computer Networks, Categories of Social Computing Application, Facebook and YouTube, Potential Issues, Statistical Analysis

\section{Introduction}

A number of social computing technologies are motivating an intense progress of the social networks. All of these social networks share a larger amount of community development, subscriber level satisfaction foundation, and a diversity of additional features. Social computing is a medium where researcher found various issues complained by the users. It is necessary for researcher to understand the significant impact of social media in users' privacy, basic communication shifts, others collaboration with social computing, security issues and commerce and business trends [1]. A huge amount of latest software applications and services that enable social computing networks to take mutual action and online social contact with rich exchange of interactive program, data information and advancement of comprehensive awareness have originated by these Web domains, for instance, Facebook, Twitter, LinkedIn, Wikipedia, peer to peer networks, research gates, Google scholar, WhatsApp, Skype, IMO, YouTube, daily motions, open source groups and online business networks. Many of the popular online social and academic networks have been rising intensely like YouTube and Facebook [2]. Computing moves computing network to the era of telecommunication and data networks and allows various subscribers with relatively low technical complexity in using the Web, to share their creativeness task, social collaboration, the knowledge, and experiences for mutual development of innovative tools, distribute important data and its publicity, and integrate joint trading control. Many social network groups will work for the transformation of market supremacy and analyze the users' inputs regarding their trading policies [3]. Social computing paradigm characterizes a novel research boundary for information systems. For instance, it provides numerous features for software improvement and the new way for users' process [4]. The user interaction with information is more dynamic by using the variety of data information domains and wide range of computing devices. In social computing environments where the users interact with new information with multiple information domains and devices, while they also faced various issues during accessing the web [5]. In the practice of learning social computing, concerns about computing are scalability, quality, security, and interoperability. This research paper explores the issues on the social networks and 
complaints by the users. In Pakistan, a huge number of subscribers use theses web sites for acquiring the data and accessing multimedia information on daily bases. Even these social sites have been used for commercial and non-commercial proposes. Many social applications and services facilitate the user for collecting available online information and interaction between database domains. Facebook and YouTube have investigated and highlighted the potential issues on these social network sites. Facebook and YouTube are the most widespread applications used throughout the world where users receive and disseminate their important information. Billions of users have observed on social networks and a vast number of users choose Facebook and YouTube for obtaining and transmitting their data and multimedia services. Both social web sites provide user friendly interfaces to share their information among various social groups and societies on Internet. These social networks provide many benefits to their users for example easy interface, fast data transmission, vast bandwidth, vast coverage and uninterrupted communication channels. On the other sites user faced some serious issues on these social web sites. The rest of this paper is planned as follows: Section 2 offers an overview of computer networks; Section 3 classifies the usage of social computing application; Section 4 gives a brief overview of the Facebook and YouTube; Section 5 statistically analyzes the potential issues related with social computing application and Section 6 draws the conclusion.

\section{Computer Networks}

Computer and communication mediums are essential networks for social application such as connecting societies, folks, students and corporate sector, universities and various social application globally [6]. A number of social organizational structure should not be prominent without integration of social medium as a basic communication entity. The computer networks play a very important role in connectivity among those application. These network facilitated network communication mediums to users, subscribers and active participants to share the knowledge, acquired the knowledge, run businesses, increase incomes and generate more revenue for their communities [7]. The new tool have been integrated with computer internet to connecting societies, fragment composite networks to help the unfamiliar computer users. Figure 1 shows the various wired and wireless networks used by the users' active on social application.

Decades ago computer machines were not performing their social function on networks most of computer machine put up alone for tasking. Later, the computer experts introduce the human computer interaction (HCI) systems with more interfaces and users friendly application for computer user's help. In 1960s the computer user starting to transfer their data on machine to machine mechanism. The communication fashion began to expand over the local boundaries of the computer system suck as in 1980s the propagation of E-mail and in 1990s an extensive growth of electronic data have been noticed on the Internet and many others thing also together with internet and the individual computer systems are also being synchronized with internet. Now the computer machines are tightly coupled with the communication medium either the networks 


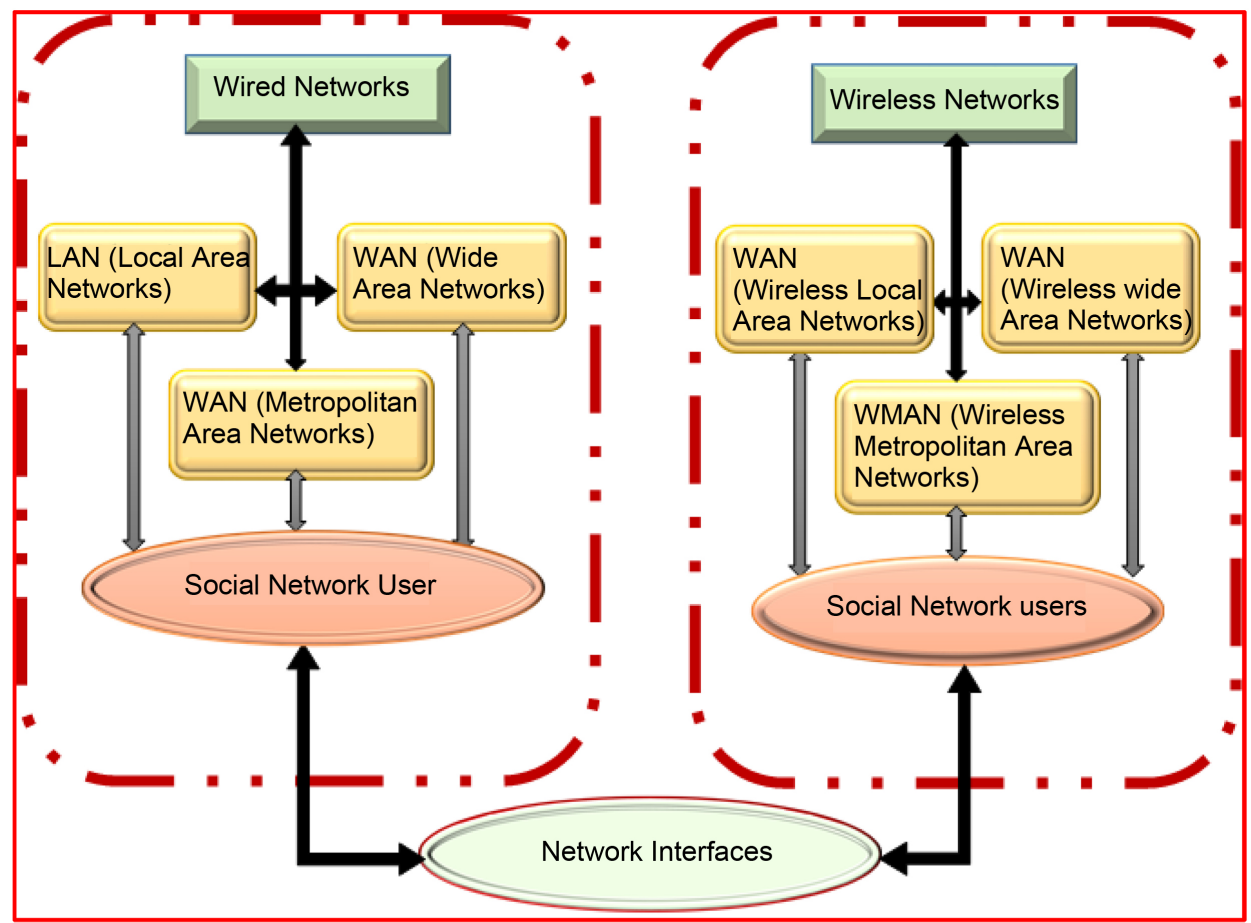

Figure 1. Wired and wireless networks for social applications.

have wired and wireless connectivity. A number of social application are being running on these networks for sharing information and operating the individual, corporate and industrial businesses. Several corporations are has their remote offices in different places with multiple employees with multiple nature of task including multiple heads. The tree of organizational worker is divided into multiple shifts. Before communication networks the heads and supervisor of organization has physically presences relationship. Now the trend is completely changed by computer networks and particular by the social networking.

\section{Categories of Social Computing Applications}

Social computing transform the trend of computer networking and strength individual subscriber relatively the advancement of technologies. Through the available economical web application and social networking the users are apparently shows their abilities, creativity, social activities, and social interactions with the other societies on the other end of network [8]. The users easily retrieved and disseminated their information globally via social media. Social media act as a fast tool for sharing information, multimedia data, voice, photographs and text. The available social networking application also changed the preferences of people regarding their priorities, likes and dislikes and even daily routines [9]. Figure 2 demonstrated the types of social network.

\subsection{Daily Motion}

Daily motion is type of social media where users almost discovery different methods to 


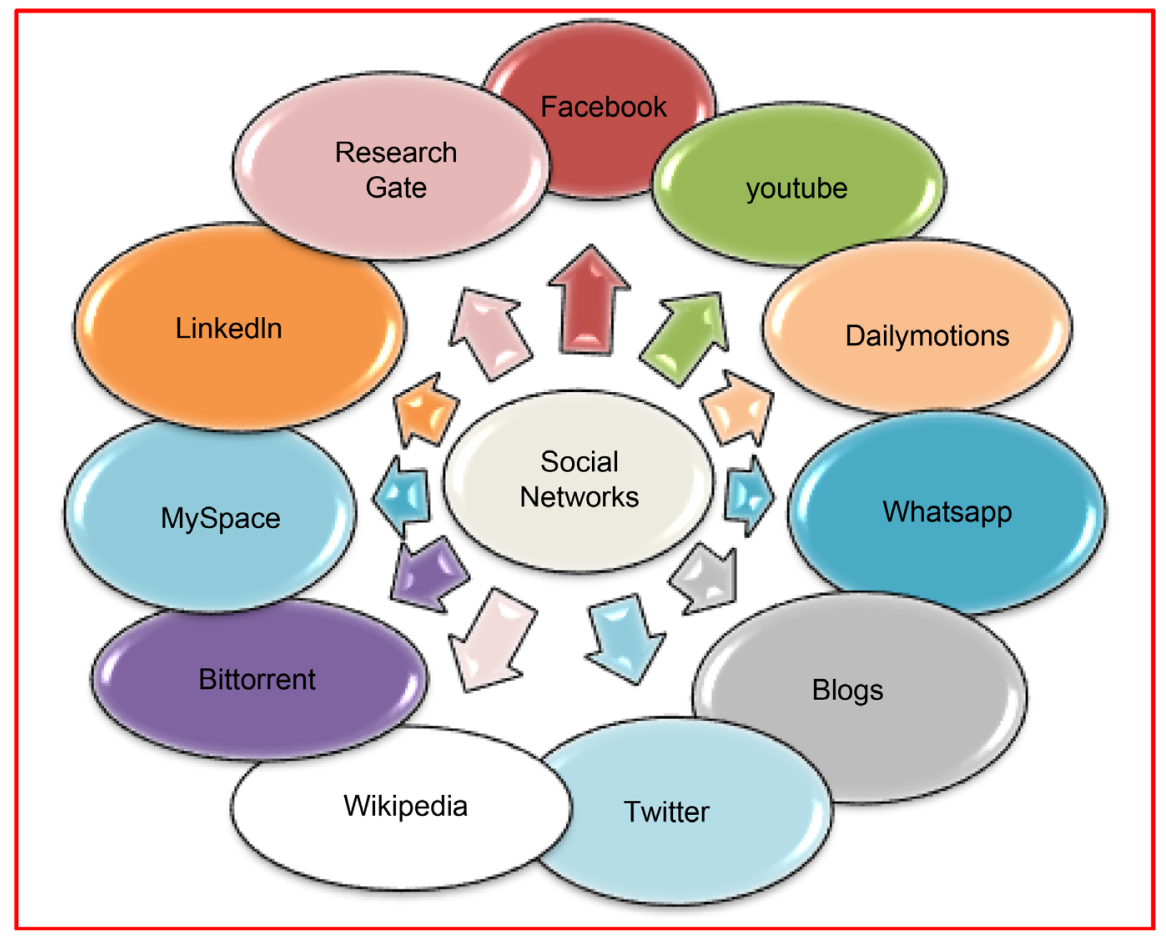

Figure 2. Number of social networks.

get, dissemination, share and engage the other users globally through online video. It is a power social application where user can upload and share personal, commercial and non-commercial videos with the other social groups in social media [10]. Daily motion is the top one of the social multimedia communication network throughout the globe. It provide best quality video for active users.

\subsection{WhatsApp}

With the invention of messaging on mobile communication network the subscribers feel about the security of their instant messages to other regions. The traditional offline messages are in dangers of their locations [11]. The users need an application where they know about the status of their instant messages sending to other networks. That's why, WhatsApp application is developed by developer, it allows mobile subscribers to send their real time SMS to various groups of individuals [11]. WhatsApp support the real time text, videos, audio and group on its interface and provide a fast communication medium to active users. Both facilities online and offline are available on WhatsApp interface.

\subsection{Blogs}

The concept of blog social communication had been introduced in late 1990s. It is derived from the Web logs [12]. It was a revolutionary period for journalism industry due to advent of Blogs because many large and small groups and individual authors focused to publish their articles, topics on line. Blogs as assumed of online journals, be- 
cause it provide easy web interface to authors and allow to create a groups, communities for online discussion. It is also used for public campaigns such as politician run their campaigns via online speeches.

\subsection{Twitter}

Twitter is also a new developed social application for disseminating the information on social networks. It is new born Microblogging application on social media but it is fast and growing application. The twitter subscribers tweet about news, topic and highlight within limit of 140 words and monitor the others to receive their tweet topics, news and highlights [13]. It is also a social web site it is emerged as a new communication social channel for network users. In twitter subscribers follow the others subscribers are called followed. Being a follower on twitter the users send and received the messages called as tweet [14].

\subsection{Wikipedia}

Wikipedia is most referencing social web site for every kind of human being either, they are students, teachers, researchers, industrialist, business man, journalist and authors. Wikipedia is itself an online encyclopedia available on internet [15]. It used a stranded data base and web browser that facilitate to create and edit the articles, topics and news. It was introduced in 2001 and from its day one it has been a very popular social application for information sharing. 64,000 active authors with different languages handover their services to Wikipedia. The quantity of English articles in this social web application is around 1.9 million and nearly 19,000 addition of new articles on daily basis [16].

\subsection{Bit Torrent}

Bit Torrent is also a kind of social network, it is a peer to peer delivery social site. It cannot allow to single peer to retrieve information and also do not allowed to share its bandwidth while another user downloading information from another site [17]. This behavior make it ineffective and listed in non-corporative social medium for I formation sharing. Maximum P2P data distribution organisms are planned to be exposed, some peer can link and one peer can possibly interconnect to other peer in the organism. The accurate operation of any Peer to peer arrangement depend on assistance between the nodes. But in bit torrent do not provide both options at the same time for example, if any one select to download data records cannot upload any type of data to preserve bandwidth.

\subsection{Myspace}

Myspace is the another most famous social network sites for users where they can send their videos, making friends groups, personal profiles, photos and music. It was the largest social networking site during 2005 to 2009 throughout the world [18]. Myspace was surpassed by Facebook in the number of unique world wide-ranging users and visitors. 


\subsection{LinkedIn}

LinkedIn social network site is design for business men, researcher, professionals and individuals. It has gaining popularity and repaid growth from its beginning. It is also social online network where allows professional users, businessmen and researcher create their own profile and invite other to join or be a part of social network [19]. With the rapid of social network the users are also grow up quickly by endorsing each other's. The LinkedIn social media become enhanced the users profiles, users curriculum vita and create industrial links to career developments [20].

\subsection{Research Gate}

Research Gate is important social network for academic researchers and scholars, it allows users to create their profile and published their research work on interface. It provide innovate way for research scholars to disseminate their research and linked it to globally to other scholars [21]. It also changes the communication methods of researcher and provide an open access to various articles. The research articles in Research Gate has broadly reflect existing research areas by different researchers. It has also a good ranking position in academia research social sites [22].

\section{Overview of YouTube and Facebook}

\subsection{YouTube}

YouTube is one of the top recognized public software platforms. Planned for common internet operators to upload and download high and low-resolution videos and audios. it has seen outstanding development, and has advanced into social culture paradigm. That energies quick distribution of famous multimedia application worldwide. Substitute platforms for upload and dissemination of video and audio be present in Google and several offshore social sites. However, none of them has become as resilient trademark like as YouTube. This achievement ultimately led to Google procuring it rather than challenging with YouTube [23]. it is currently a platform not only for common video and audio clips but it is also have been used for commercial video application produced by commercial industry for example, games software application, musical application, academia video, online video lectures, political activity video, ceremony videos, products videos and guiding videos. In the previous era, the use ability of the Internet beyond domestic limitations and as well for the global connectivity between nations [24]. Now present era has social computing application that permit to discontinuity of the numerous obstacles [25]. Figure 3 represent the interface of YouTube.

The simple example of collecting and be updates globally is vast spreading coverage of electronic media news, sports news, speech and other activism which are controlled in broadcasting globally due to many reason or ownership rights and also bring the novel stories and news which are blocked by the conventional electronic media or print media from the attention of general public. Thus this application breakdowns both official and un-official restriction [26]. The total amount of video watched in hours on YouTube per month is around 900 million and 10,113 YouTube video clips produced 


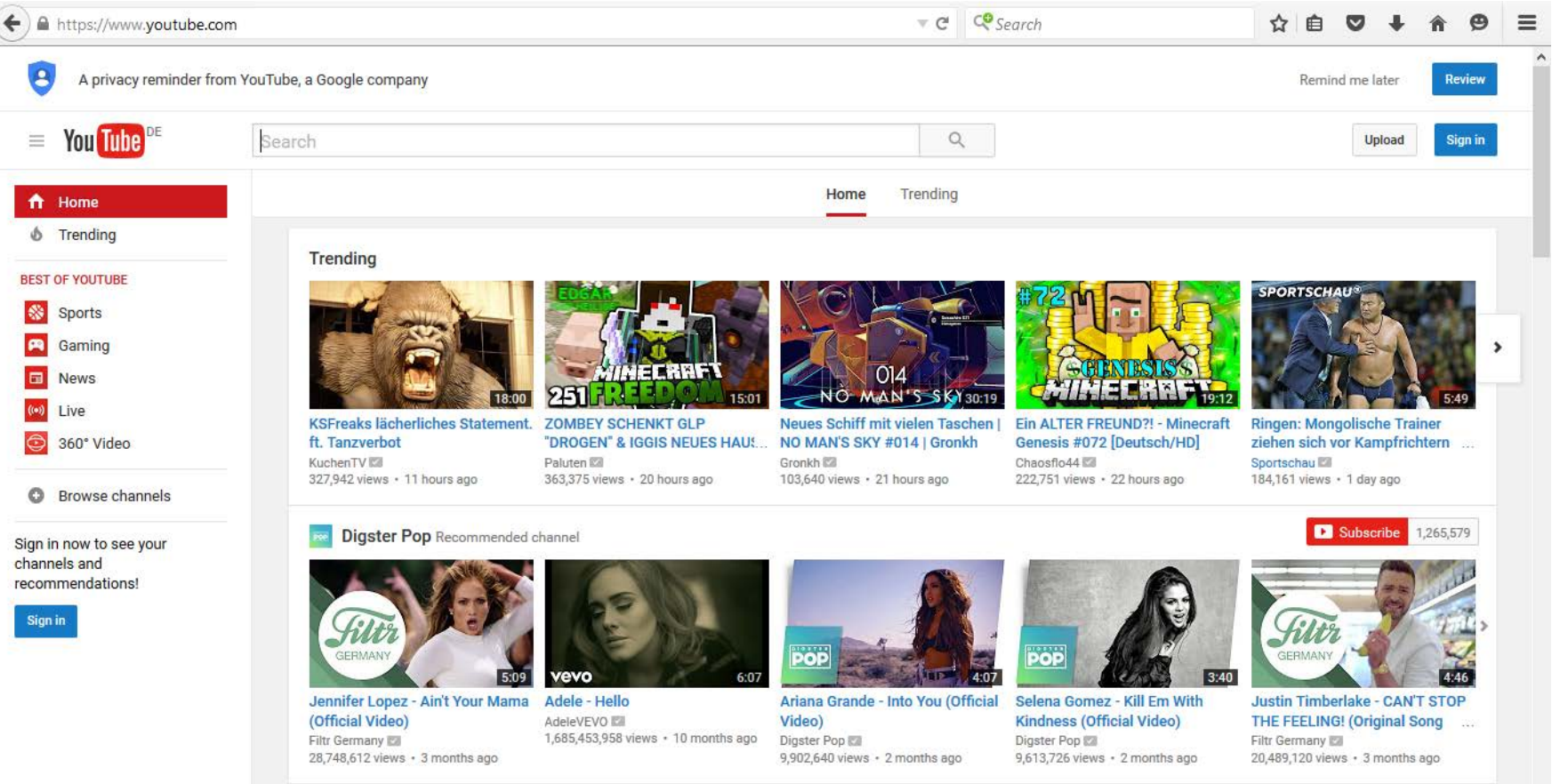

Figure 3. YouTube interface.

over 1 billion viewers. The total number from $80 \%$ of YouTube viewers are from outside of the United States of America. A huge number of mobile user also views the video clips on YouTube by their smart cell phones. Table 1 shows the statistics of YouTube users, watched video on YouTube, uploaded videos, watched per months videos, generated videos, mobile YouTube videos clips. Hours on YouTube per month is around 900 million and 10,113 YouTube video clips produced over 1 billion viewers. The total number from $80 \%$ of YouTube viewers are from outside of the United States of America. A huge number of mobile user also views the video clips on YouTube by their smart cell phones. Table 1 shows the statistics of YouTube users, watched video on YouTube, uploaded videos, watched per months videos, generated videos, mobile YouTube videos clips.

\subsection{Facebook}

Facebook is an online potential social area network, it has experienced exponential progress in membership in recent few years. This social network offer elegant resources for interfacing, interaction, communication and sharing multimedia information between Facebook users. It also have provide facilities to Schools, colleges and universities fellows to exchange the educational information [27]. A huge number of young adults expands more time on usage of Facebook for various purposes. However, school level student also well-known about uses of social network. Facebook is most favorite social site for students, approximately after 30 minutes every student use Facebook throughout the whole day as a necessary part of their everyday routine. The users interconnected on Facebook using with many approaches, in which they created cheat groups, 
Table 1. YouTube statistics.

\begin{tabular}{|c|c|c|c|c|c|c|}
\hline S.N & $\begin{array}{c}\text { YouTube } \\
\text { users }\end{array}$ & $\begin{array}{l}\text { Watched } \\
\text { video on } \\
\text { YouTube }\end{array}$ & $\begin{array}{l}\text { Watched } \\
\text { per months } \\
\text { videos }\end{array}$ & $\begin{array}{l}\text { Views video } \\
\text { on mobile } \\
\text { YouTube }\end{array}$ & $\begin{array}{c}\text { Generated } \\
\text { videos }\end{array}$ & $\begin{array}{l}\text { Support } \\
\text { languages }\end{array}$ \\
\hline Total users & $1,300,000,000$ & & & & & \\
\hline Single day & & 5 billions & & & & \\
\hline One month & & & 900 billions & & & \\
\hline $\begin{array}{l}\text { Mobile } \\
\text { Users }\end{array}$ & & & & $1,000,000,000$ & & \\
\hline $\begin{array}{c}\text { Generated } \\
\text { video }\end{array}$ & & & & & 1 billions & \\
\hline Languages & & & & & & 76 \\
\hline
\end{tabular}

audio conversion, video clips and online face to face chatting. Figure 4 shows the proposed interface of Facebook application.

Social network offers the significant environment for the social, sensitive, and intellectual growth of adults and also used in secretarial for a huge slice of their time. One kind of online network service that has grown-up quickly in popularity and acceptance in current years is social computing networks on the Internet. Social networks websites, such as Facebook, LinkedIn, twitter, YouTube, and daily motions are member-based Internet societies that permit operators to post summery material, user profile data such as a user name, user Id, User cell phone and pictures, and to interconnect with others in modern means such as transfer online messages on private inbox or publically [28]. The indicator shows the active timeline Facebook users monthly in the rest of the world from 2008 to 2016 are 1.71 billion. Figure 5 shows the 4 th quarters of year's active user participation on Facebook. Figure 5 demonstrated the active users on Facebook.

\section{Statistical Analysis of Issues on Facebook and Youtube}

In this research paper we had investigated the related issues faced by active social media users in different cities of Pakistan. There are number of social networks used for disseminating and retrieving the information however the frequent used social networks all over the world is Facebook and YouTube. Pakistan is one of the country where huge number of active users use these social web sites to share and disseminate the official and unofficial information. In this research paper a survey has been conducted through distribution of survey form among the students, teachers, professionals, and workers, commercial, non-commercial and domestic Facebook and YouTube users. The survey form indicated the issues occurred on social web sites where an active users give their potential inputs about the potential issues occurred during social web site browsing. Various and most populated cities in Pakistan have been selected for conducting surveys. Where large number of active users participated and highlight their serious concern on these social websites. Six more populated cities such as Karachi, Hyderabad, 


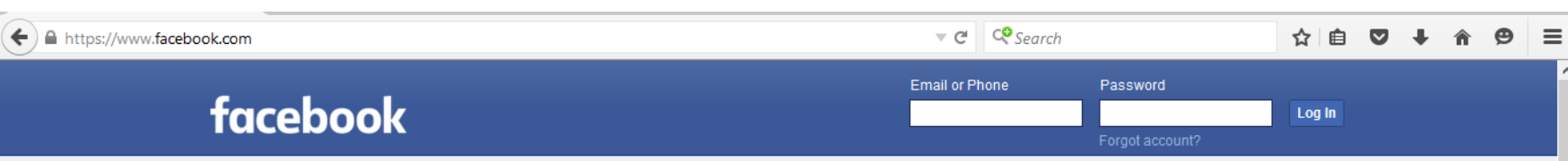

\section{Connect with friends and the world around you on Facebook.}

See photos and updates from friends in News Feed.

Share what's new in your life on your Timeline.

Find more of what you're looking for with Facebook Search.

\section{Sign Up}

It's free and always will be.

\begin{tabular}{l}
\hline First name Last name \\
Mobile number or email \\
Re-enter mobile number or email \\
New password
\end{tabular}

Birthday

\begin{tabular}{l|l|l|l} 
Month $\vee$ & Day $\checkmark$ & Year $\checkmark$ & Why do Ineed to provide my \\
birthday?
\end{tabular}

$\bigcirc$ Female $\bigcirc$ Male

By clicking Create Account, you agree to our Terms and that you

have read our Data Policy, including our Cookie Use.

\section{Create Account}

Create a Page for a celebrity, band or business.

Figure 4. Facebook interface.

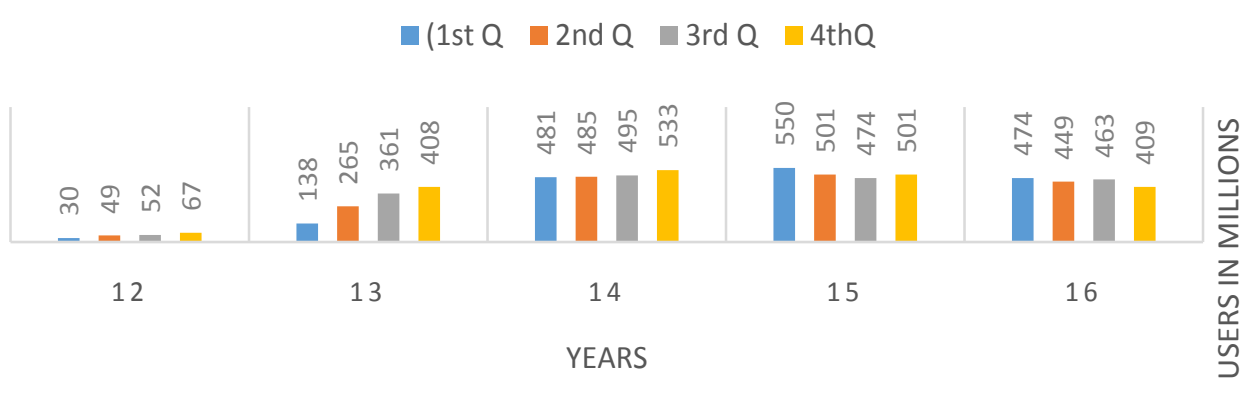

Figure 5. Active user statistics on Facebook.

Lahore, Islamabad, Quetta and Peshawar have been selected for leading survey. During a survey number of user participated and give their inputs regarding the potential issues on Facebook and YouTube. Survey method is comprised with Total users, Active users, Surveys participant, Complainant users, Non-Complainant users and Address complains. A survey form had been distributed among $55 \%$ to $80 \%$ users in different cities. The active users were $35 \%$ to $60 \%$ and participant users were up-to 48 to 65 . From total users' different question have been asked through questioner forms such how much users faced the privacy and security issues, controversial multimedia issues, unwanted advertisement content, and desire data availability on time and fake accounts IDs issues. The result was from $30 \%$ to $50 \%$ users, put complains and $11 \%$ to $30 \%$ users, do not registered complains even though they were faced some issues but only few complains had been addressed by the social network administrators. This survey is conducted on the bases of qualitative and quantitative methods where some professional institutes have been selected for indicating the issues and some other general users 
participated on this process.

\subsection{Privacy and Security Issues}

The variation in behavior impact on the privacy and security of personal data on an open interface. In this research we conducting a survey from the users of Facebook and YouTube and obtaining a concrete statistic from different cities of Pakistan. The open interface must have the ability to control and monitor the injecting and ejecting information from these social sites [29]. However the statistic are different from the reality. Table 2 shows the statistical number of user taken from the various cities of Pakistan. Where number of users shows their grievance regarding the privacy and security issues on Facebook and YouTube [30]. A survey form had been distributed in most populated cities of Pakistan where active user, how much users participated in survey, how much users registered their complaint, how much silent users and how much complaint have been address by the social network experts. Figure 6 shows the statistical variation of Facebook and YouTube users.

Table 2. Users on Facebook \& YouTube.

\begin{tabular}{ccccccc}
\hline Cities & $\begin{array}{c}\text { Total } \\
\text { user }\end{array}$ & Active user & $\begin{array}{c}\text { Survey } \\
\text { participants }\end{array}$ & Complainant & Non-complainant & $\begin{array}{c}\text { Address } \\
\text { complains }\end{array}$ \\
\hline Karachi & 80 & 60 & 65 & 50 & 20 & 25 \\
Hyderabad & 60 & 45 & 50 & 38 & 22 & 15 \\
Lahore & 70 & 55 & 60 & 40 & 30 & 20 \\
Islamabad & 65 & 58 & 63 & 45 & 25 & 19 \\
Quetta & 50 & 38 & 40 & 39 & 11 & 12 \\
Peshawar & 55 & 35 & 48 & 30 & 25 & 15 \\
\hline
\end{tabular}

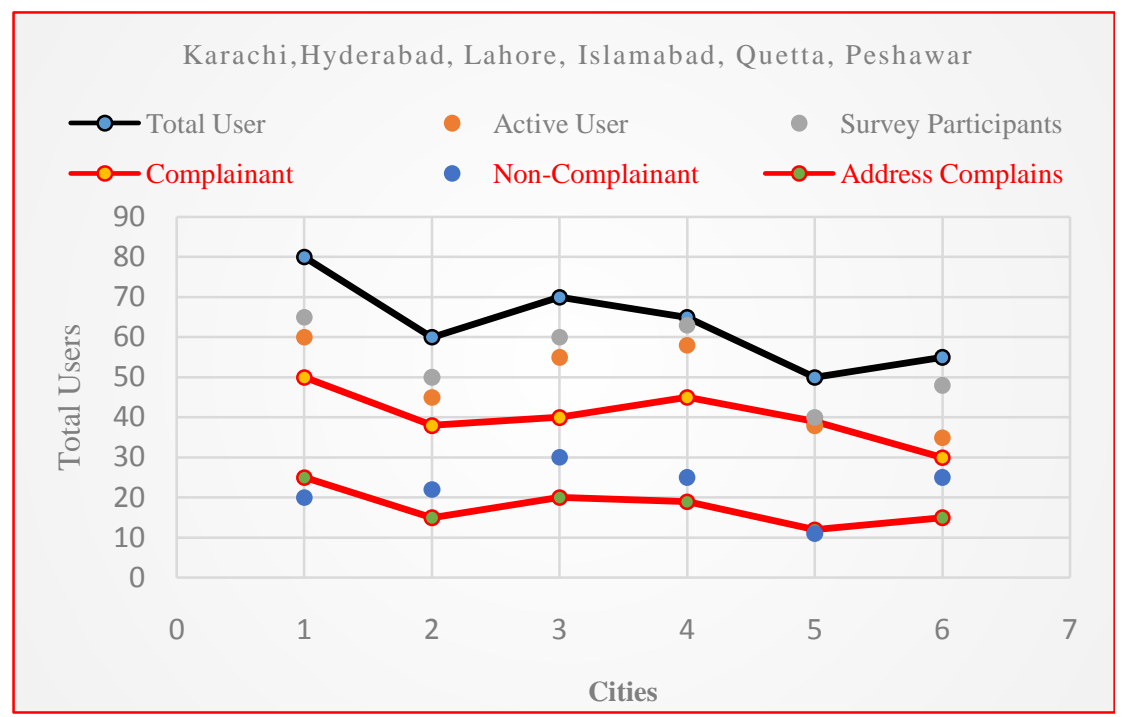

Figure 6. Security and privacy statistics. 


\subsection{Controversial Multimedia Services Issues}

Another issue raised by the users is upload and posted a multimedia services without any authentication. Whether these multimedia services create a conflict between users, societies, families and individual self-respect. The strength of social media is as a communication medium to foster multimedia information, videos, discussion to their users. Two of the most popular social media managed by the white house such as Facebook and YouTube [31]. See Figure 7.

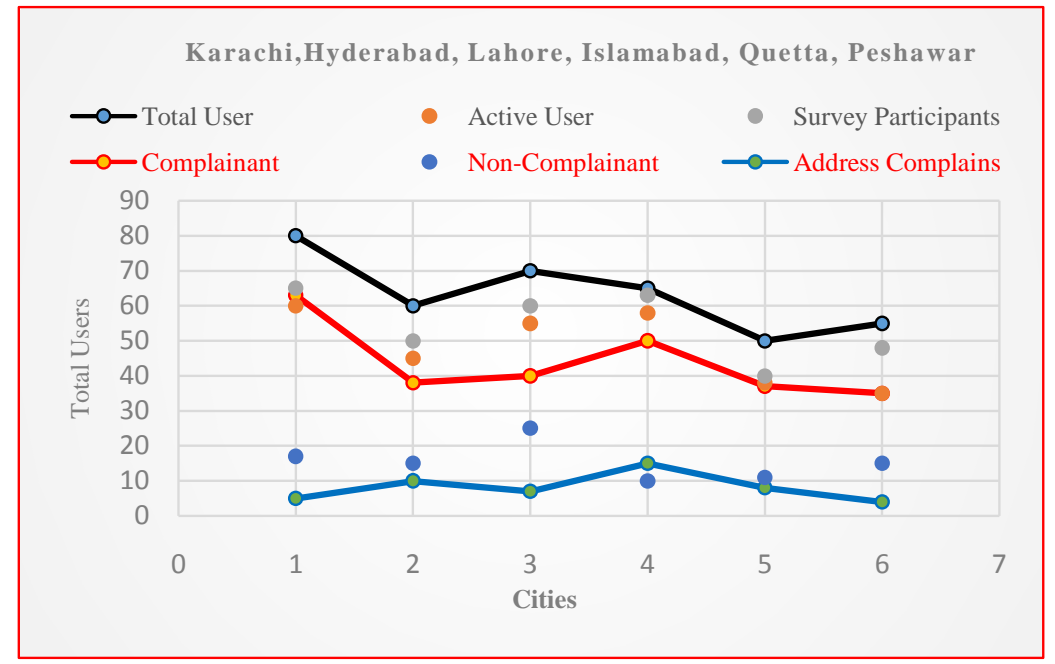

Figure 7. Controversial multimedia services issues statistics.

\subsection{Advertisements Content Issues}

Social media provide an easy interface to users for interactive communication and data dissemination to other communities on internet. Different organization preferred social media to lunch their product online not only lunching but also used for advertisement of many products [32]. Sometimes the users found unnecessary advertisement on their timeline or during uploading and downloading of any multimedia services. The social media has huge amount of unnecessary advertisements on Facebook and YouTube which caused the more utilization of bandwidth and slow the browsing speed and throughput of network. Figure 8 shows the complained statistics of unnecessary advertisement during our surveys in various cities.

\subsection{Data Availability Issues}

The topical introduction of social media networks sites have caused in a larger internet bandwidth utilization for distribution of interactive program content via social websites for example Facebook and YouTube. Travelling a huge amount of multimedia information through restricted social network means remains a practical task nowadays [33]. Currently large number of Facebook and YouTube subscribers has complains against availability of desire and meaningful data on these social websites. Figure 8 represent the survey result graphs taken from various cities in Pakistan. Social websites contain 


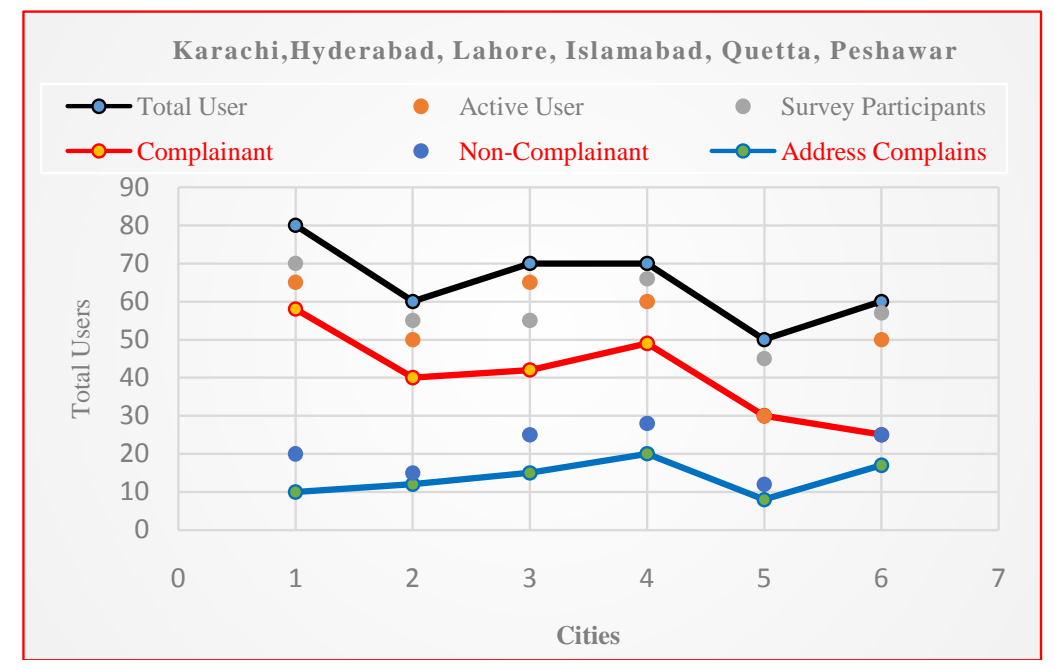

Figure 8. Advertisements content issues statistics.

web presented multimedia services, like video, audio, textual, graphics and other information, in entrance of burdens within a quite tiny interval of time when every observer broadcasts it to their nodes, who start additional spreads multimedia services to others down channels. The social site like as YouTube, which contains this multimedia information requisite to be able to adjust this outburst of access demand of information for avoiding unnecessary interruption. Figure 9 present the statistical data of various users in Facebook and YouTube.

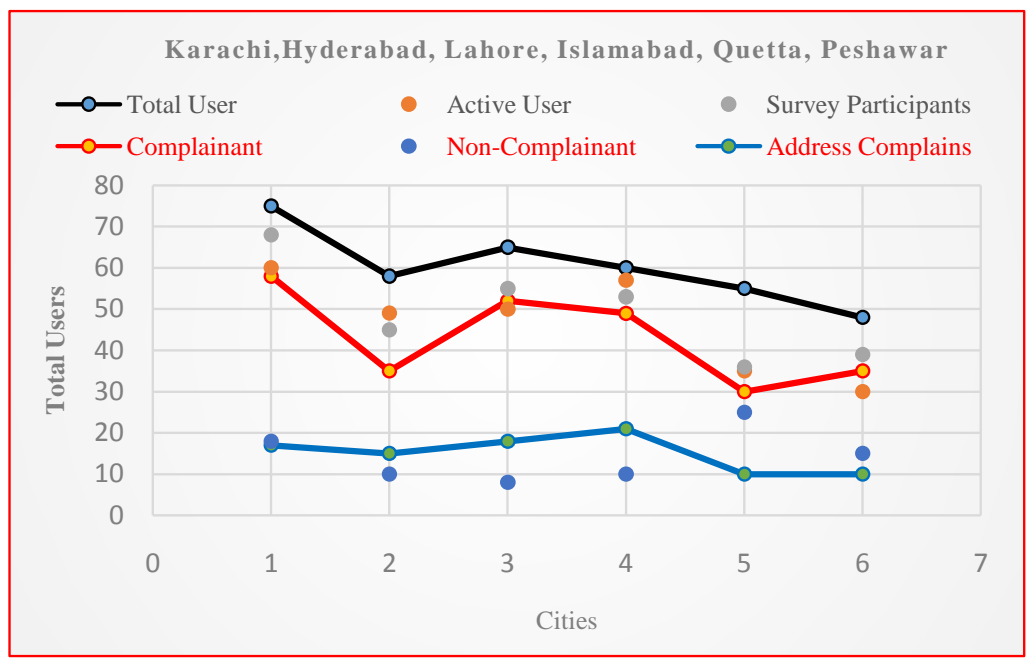

Figure 9. Data availability issues statistics.

\subsection{Fake Accounts and Multimedia Information}

The major issues faced by social media users in Pakistan has fake Facebook IDs and fabricated multimedia videos on YouTube. Mainstream users of theses social websites bear the moral and ethical irritation from the uploaded multimedia services from unidentified IDs and sources [34]. Figure 10 demonstrate the large number of internet 


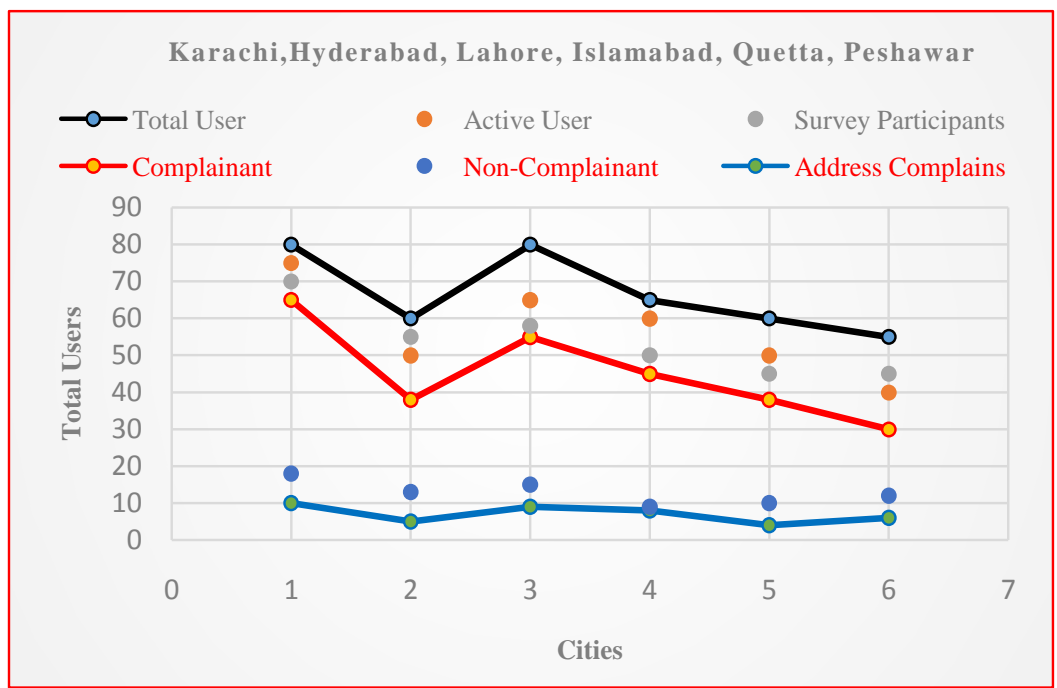

Figure 10. Fake IDS and fabricated videos statistics.

has users complains to social sites admin against these fabricated videos, audios and textual information.

\section{Conclusion}

Social media, mostly Facebook and YouTube are used as social online networks for information retrieval and dissemination. In Pakistan a huge number of users used social networks as a communication tool for their educational, commercial and non-commercial purposes. The other communities also used these social networks for their own interest. For example politicians used social networks for their election campaigns; film industry used for industrial promotion and banking sector also used for their advertisements. These social networks provide a fast communication channel for their users to share multimedia information despite the fact that these networks have some limitations regarding data security, user privacy, data integrity, fake accounts, fabricated videos, unauthenticated information, un-necessary advertisements, data availability and interface inter-operability issues. In Pakistan a maximum number of users on theses social networks complained some serious issues and challenges regarding their data. We explore some potential issues occurred in various cities of Pakistan where users put their inputs about security and other threats in social sites. Meanwhile the internet users also indicate some other challenges on social media such as cyber blackmailing, unethical data material, cybercrimes and personal identity issues. The users also registered their complaints to social network administration. However, the social network administration took some serious action against the challenging issues but mostly ignored the users' complaints. The statistics shows the percentage of, total, active, survey participant, complainants, and non-complainants users on social networks respectively.

\section{References}

[1] Acquisti, A. and Gross, R. (2006) Imagined Communities: Awareness, Information Sharing, 
and Privacy on the Facebook. Springer Berlin, Heidelberg, 36-58.

http://dx.doi.org/10.1007/11957454_3

[2] Almadhoun, N. and Dominic, P. (2011) Perceived Security, Privacy, and Trust Concerns within Social Networking Sites: The Role of Information Sharing and Relationships Development in the Malaysian Higher Education Institutions' Marketing. IEEE International Conference on Control System, Computing and Engineering, 25-27 November 2011. http://dx.doi.org/10.1109/iccsce.2011.6190564

[3] Capocci, A., Servedio, V., Colaiori, F. and Buriol, L. (2006) Preferential Attachment in the Growth of Social Networks: The Internet Encyclopedia Wikipedia. Physical Review E, 74, Article ID: 036116. http://journals.aps.org/pre/abstract/10.1103/PhysRevE.74.036116 http://dx.doi.org/10.1103/physreve.74.036116

[4] de Castro, L. (2007) Fundamentals of Natural Computing: An Overview. Physics of Life Reviews, 4, 1-36. http://www.sciencedirect.com/science/article/pii/S1571064506000315 http://dx.doi.org/10.1016/j.plrev.2006.10.002

[5] Chakraborty, N. (2012) Activities and Reasons for Using Social Networking Sites by Research Scholars in NEHU: A Study on Facebook and Research Gate.

http://ir.inflibnet.ac.in/handle/1944/1666

[6] Church, K. and de Oliveira, R. (2013) What's up with Whatsapp? Comparing Mobile Instant Messaging Behaviors with Traditional SMS. 15th International Conference on $\mathrm{Hu}$ man-Computer Interaction with Mobile Devices and Services, 352-361.

http://dl.acm.org/citation.cfm?id=2493225

[7] Daily Motion. http://knowem.com/websites/DailyMotion

[8] Galuba, W., Aberer, K. and Despotovic, Z. (2010) Leveraging Social Networks for Increased Bittorrent Robustness. 7 th IEEE Consumer Communications and Networking Conference. http://ieeexplore.ieee.org/xpls/abs_all.jsp?arnumber=5421823

[9] Halpern, D. and Gibbs, J. (2013) Social Media as a Catalyst for Online Deliberation? Exploring the Affordances of Facebook and YouTube for Political Expression. Computers in Human Behavior, 29, 1159-1168.

http://www.sciencedirect.com/science/article/pii/S0747563212002762 http://dx.doi.org/10.1016/j.chb.2012.10.008

[10] Hansen, S., Berente, N. and Lyytinen, K. (2009) Wikipedia, Critical Social Theory, and the Possibility of Rational Discourse 1. The Information Society. http://www.tandfonline.com/doi/abs/10.1080/01972240802587562

[11] Hinduja, S. and Patchin, J. (2008) Personal Information of Adolescents on the Internet: A Quantitative Content Analysis of MySpace. Journal of Adolescence, 31, 125-146. http://www.sciencedirect.com/science/article/pii/S0140197107000541 http://dx.doi.org/10.1016/j.adolescence.2007.05.004

[12] Hookway, N. (2008) "Entering the Blogosphere": Some Strategies for Using Blogs in Social Research. Qualitative Research, 8, 91-113. http://qri.sagepub.com/content/8/1/91.short http://dx.doi.org/10.1177/1468794107085298

[13] Java, A., Song, X., Finin, T. and Tseng, B. (2007) Why We Twitter: Understanding Microblogging Usage and Communities. Workshop on Web Mining and Social Network Analysis, 56-65. http://dl.acm.org/citation.cfm?id=1348556 http://dx.doi.org/10.1145/1348549.1348556

[14] Kwak, H., Lee, C., Park, H. and Moon, S. (2010) What Is Twitter, a Social Network or a News Media? Proceedings of the 19th International Conference on World Wide Web, 591600. http://dl.acm.org/citation.cfm?id=1772751

[15] Lin, N. (1999) Building a Network Theory of Social Capital. Connections, 22, 28-51. 
http://www.insna.org/PDF/Connections/v22/1999_I-1-4.pdf

[16] Matthews, J. and Macaskill, L. (2015) Engaging the YouTube Learner: Promoting Home Economics through Videos. International Journal of Home Economics, 8, 53-63. https://search.informit.com.au/documentSummary;dn=542633519397031;res=IELHSS

[17] Memon, S., Mahar, S., Das Dhomeja, L. and Pirzado, F. (2015) Prospects and Challenges for Social Media in Pakistan. 2015 International Conference on Cyber Situational Awareness, Data Analytics and Assessment (CyberSA), London, 8-9 June 2015, 1-5. http://dx.doi.org/10.1109/CyberSA.2015.7166124

[18] Messinger, P., Stroulia, E., Lyons, K. and Bone, M. (2009) Virtual Worlds-Past, Present, and Future: New Directions in Social Computing. Decision Support, 47, 204-228.

http://www.sciencedirect.com/science/article/pii/S016792360900061X http://dx.doi.org/10.1016/j.dss.2009.02.014

[19] Montgomery, J. (1991) Social Networks and Labor-Market Outcomes: Toward an Economic Analysis. The American Economic Review, 81, 1408-1418. http://www.jstor.org/stable/2006929

[20] Nov, O. and Wattal, S. (2009) Social Computing Privacy Concerns: Antecedents and Effects. The SIGCHI Conference on Human Factors in Computing, Boston, 4-9 April 2009, 333-336. http://dl.acm.org/citation.cfm?id=1518754 http://dx.doi.org/10.1145/1518701.1518754

[21] Parameswaran, M. and Whinston, A. (2007) Research Issues in Social Computing. Journal of the Association, 8, 336-350.

http://search.proquest.com/openview/89b0cf3f4fd60f335ed84c4aa60303f5/1?pq-origsite=gs cholar

[22] Parameswaran, M. and Whinston, A. (2007) Social Computing: An Overview. Communications of the Association for Information Systems, 19, 762-780. http://aisel.aisnet.org/cgi/viewcontent.cgi?article $=2680 \&$ context=cais

[23] Pempek, T.A., Yermolayeva, Y.A. and Calvert, S.L. (2009) College Students' Social Networking Experiences on Facebook. Journal of Applied Developmental Psychology, 30, 227238. http://dx.doi.org/10.1016/j.appdev.2008.12.010

[24] Rader, E. (2014) Awareness of Behavioral Tracking and Information Privacy Concern in Facebook and Google. Symposium on Usable Privacy and Security (SOUPS), Menlo Park, 9-11 July 2014, 51-68. https://www.usenix.org/sites/default/files/soups14_proceedings.pdf\#page $=58$

[25] Russell, M. (2013) Mining the Social Web: Data Mining Facebook, Twitter, Linked In, Google ${ }^{+}$, GitHub, and More. https://books.google.com.pk/books?hl=en\&lr=\&id=_VkrAQAAQBAJ\&oi=fnd\&pg=PR4\&d $\mathrm{q}=$ linkedIn+\&ots=JqpsrFUwgK\&sig=JIyDEfzwHHLeh227cmfORa6AGTw

[26] Shah, C. (2008) Tubekit: A Query-Based Youtube Crawling Toolkit. Proceedings of the 8 th ACM/IEEE-CS Joint Conference, Pittsburgh, 16-20 June 2008, 433-433.

http://dl.acm.org/citation.cfm?id=1378980 http://dx.doi.org/10.1145/1378889.1378980

[27] Skeels, M. and Grudin, J. (2009) When Social Networks cross Boundaries: A Case Study of Workplace Use of Facebook and Linkedin. Proceedings of the ACM 2009 International Conference on Supporting Group Work, Sanibel Island, 10-13 May 2009, 95-104.

http://dl.acm.org/citation.cfm?id=1531689 http://dx.doi.org/10.1145/1531674.1531689

[28] Smith, A., Fischer, E. and Yongjian, C. (2012) How Does Brand-Related User-Generated 
Content Differ across YouTube, Facebook, and Twitter? Journal of Interactive Marketing, 26, 102-113. http://www.sciencedirect.com/science/article/pii/S1094996812000059 http://dx.doi.org/10.1016/j.intmar.2012.01.002

[29] Snelson, C., Rice, K. and Wyzard, C. (2012) Research Priorities for YouTube and VideoSharing Technologies: A Delphi Study. British Journal of Educational, 43, 119-129. http://onlinelibrary.wiley.com/doi/10.1111/j.1467-8535.2010.01168.x/full http://dx.doi.org/10.1111/j.1467-8535.2010.01168.x

[30] Soysa, D., Chen, D. and Au, O. (2013) Predicting YouTube Content Popularity via Facebook Data: A Network Spread Model for Optimizing Multimedia Delivery. 2013 IEEE Symposium on Computational Intelligence and Data Mining (CIDM), Singapore, 16-19 April 2013, 214-221. http://ieeexplore.ieee.org/xpls/abs_all.jsp?arnumber=6597239 http://dx.doi.org/10.1109/CIDM.2013.6597239

[31] Spartz, J., Su, L., Griffin, R. and Brossard, D. (2015) YouTube, Social Norms and Perceived Salience of Climate Change in the American Mind. Environmental Communication, 1-16.

http://www.tandfonline.com/doi/abs/10.1080/17524032.2015.1047887 http://dx.doi.org/10.1080/17524032.2015.1047887

[32] Thelwall, M. andKousha, K. (2015) Research Gate: Disseminating, Communicating, and Measuring Scholarship? Journal of the Association for Information Science and Technology, 66, 876-889. http://onlinelibrary.wiley.com/doi/10.1002/asi.23236/full http://dx.doi.org/10.1002/asi.23236

[33] Wellman, B. (2001) Computer Networks as Social Networks. Science, 293, 2031-2034. http://science.sciencemag.org/content/293/5537/2031.short http://dx.doi.org/10.1126/science.1065547

[34] Zimmer, C. (1986) Entrepreneurship through Social Networks. The Art and Science of Entrepreneurship. Ballinger.

http://www.academia.edu/download/32500636/Aldrich_and_Zimmer_entshp_thru_social_ networks_1986.pdf

\section{Submit or recommend next manuscript to SCIRP and we will provide best service} for you:

Accepting pre-submission inquiries through Email, Facebook, LinkedIn, Twitter, etc. A wide selection of journals (inclusive of 9 subjects, more than 200 journals)

Providing 24-hour high-quality service

User-friendly online submission system

Fair and swift peer-review system

Efficient typesetting and proofreading procedure

Display of the result of downloads and visits, as well as the number of cited articles

Maximum dissemination of your research work

Submit your manuscript at: http://papersubmission.scirp.org/

Or contact jcc@scirp.org 